\title{
Evaluation of Antioxidant, Antimicrobial and Antimutagenic Activity with Irritation Effects of Ceramium rubrum (Red Algae) Extract
}

\author{
Adem Güner (iD*,1, N. Ülkü Karabay Yavaşoğlu ${ }^{2}$ \\ ${ }^{1}$ Giresun University, Faculty of Science and Art, Department of Biology, 28200 Güre Giresun \\ ${ }^{2}$ Ege University, Faculty of Science, Department of Biology 35100 Bornova Izmir
}

\begin{abstract}
This study was conducted to evaluate antioxidant, antimutagenic and antimicrobial activities as well as irritation/toxicity efficacy of n-hexane, chloroform and methanol extracts of the red algae Ceramium rubrum C. Agardh (1881). While spectrophotometric methods were used for the determination of total phenol and flavonoid content, antioxidant activity was evaluated by DPPH assay. Antimicrobial and antimutagenic efficacy of extracts were determined by MIC method and Ames test, respectively. Also, HET-CAM test was used for irritation/toxicity of extracts. While methanol extract was found to have higher total flavonoid and phenolic contents than the other extracts and hexane showed higher antioxidant activity than other extracts. All extracts exerted moderate antimicrobial activity against tested microorganisms as $64-256 \mu \mathrm{g} / \mathrm{mL}$. However, extracts of the algae did not show any mutagenicity or irritation effect even at the highest concentration.
\end{abstract}

\section{ARTICLE HISTORY}

Received: 18 June 2018

Revised: 19 October 2018

Accepted: 25 October 2018

\section{KEYWORDS}

Red algae,

Antioxidant,

Antimicrobial,

Ames test,

Hetcam assay

\section{INTRODUCTION}

Plant secondary metabolites or natural products are active chemical compounds that are not directly involved in the vital activities of an organism other than the primary metabolites, often produced for protection during environmental interactions. Secondary metabolites play important roles in defense against microbial pathogens, predators and abiotic stresses (drought, salinity and UV exposure), communication with other organisms and other ecological functions. This active compounds have been intensively studied since the 19th century, and especially macroalgae represents for about $20 \%$ of the compounds reported from the marine area [1].

Unlike other species, macroalgae which have dispersions in almost every part of the world have developed a superior protection mechanism to survive against many factors, particularly coastal algae, UV, wind, tides, sudden temperature changes, marine pollution and aquatic life thanks to their secondary metabolites. These active chemicals have shown many useful

CONTACT: Adem GÜNER \ ademeguner@gmail.com $\equiv$ Giresun University, Faculty of Science and Art, Department of Biology 28200 Güre, Giresun. Tel: +90 4543104011 
biological activities such as antioxidant, antiviral, antimicrobial, antifouling, anticoagulant and anticancer for human health [2].

Especially, antioxidant studies have been one of the most popular research areas of algae. Numerous studies have shown that algae can contribute to the system in different ways by preventing, delaying or eliminating of free radicals as an antioxidant resource. Algae are rich in metabolites such as carotenoids ( $\alpha$ - and $\beta$-carotene, fucoxanthin, astaxanthin), catechins, gallate, florotannins and tocopherols as well as reactive antioxidant molecules such as glutathione and ascorbate [3]. Previous studies have shown that while pireniltoluqinones obtained from Cystoseira crinita brown algae have potent radical scavenging activity [4], fluorotannins from Ecklonia stolonifera have this effect [5].

Commonly used antibiotics are less effective against certain diseases because of their different chemical structures and mechanism of action, toxin production and resistance to drugs. For this reason, the discovery of new antibiotics has a vital role. Algae extracts have been the subject of many studies in terms of antimicrobial activity and have been shown to inhibit the growth of many gram-negative and gram-positive bacterial pathogens [6,7]. Consequently, antimicrobial compounds such as oil, lipophilic compound, phenolics, alkaloids, polyphenols, halogenates and isophorone have been described [8].

The genomes of all living organisms are continuously exposed to damage by endogenous and exogenous processes. This damage leads to many diseases in the organism. The antimutagenic properties of algae phytochemicals have not been studied as intensively as in many other degenerative diseases, but effective results have been obtained. Photosynthetic pigments isolated from some algae species have been identified as chemical protection agents. In a study of the antimutagenic effects of different algae species, it was found that Caulerpa sertularioides and Spyridia filamentosa exhibit high antimutagenic activity against Salmonella typhimurium TA98 and TA100 strains [9].

In the current study, in vivo irritation/toxicity effects as well as the effects of antioxidant, antimutagenic and antimicrobial activities of the n-hexane (Hex), chloroform (Chl) and methanol (Met) extracts of Ceramium rubrum (Hudson) (red algae) were first evaluated.

\section{MATERIALS and METHODS}

\subsection{Seaweed material}

C. rubrum was collected at a depth of 1-2 $\mathrm{m}$, in a region of high light intensity, from the coastline of Urla, Izmir, in April 2013. Voucher specimen (C.rubrum) (number: 41324) were deposited in the Hydrobiology Laboratory of Ege University, Faculty of Science, Department of Biology. The samples were washed three times with tap water to remove salt, epiphytes and sand attached to the surface, then carefully rinsed with fresh water, and maintained in a refrigerator at $-20^{\circ} \mathrm{C}$.

\subsection{Preparation of extracts}

Algal samples were dried at $45^{\circ} \mathrm{C}$. Powdered material $(100 \mathrm{~g})$ was extracted subsequently with n-hexane (Hex) (purity $\geq 99.9 \%$, Merck, Darmstadt, Germany), chloroform (Chl) (purity 99.0-99.4\%, Merck, Darmstadt, Germany) and methanol (Met) (purity $\geq 99.9 \%$, Merck, Darmstadt, Germany) at room temperature in an ultrasonic bath $\left(3 \times 1 \mathrm{~L}\right.$ of each solvent, $40^{\circ} \mathrm{C}$, $24 \mathrm{~h}$ ). The combined extracts were evaporated separately for each solvent under reduced pressure by using Rotary evaporator (Heidolph300 LabroRota, Germany) to dryness and were obtained $102 \mathrm{mg}, 108 \mathrm{mg}$ and $2104 \mathrm{mg}$, respectively, from the Hex, Chl and Met extracts. 


\subsection{Determination of total phenolic and flavonoid contents}

Total phenolic content was determined by Folin-Ciocalteu method [10]. Briefly, $0.1 \mathrm{~mL}$ of extracts $(0.5 \mathrm{mg} / \mathrm{mL}$ and $1 \mathrm{mg} / \mathrm{mL})$ were mixed with $2.8 \mathrm{~mL}$ deionized water. This solution was mixed with $2 \mathrm{~mL} 2 \%$ sodium carbonate and $0.1 \mathrm{~mL}$ of $0.1 \mathrm{~N}$ Folin-Ciocalteu reagent. After incubation at room temperature for $30 \mathrm{~min}$, the absorbance of the mixture was measured at $750 \mathrm{~nm}$ against a deionized water blank on a UNICAM $8625 \mathrm{UV} / \mathrm{V}$ is spectrophotometer. Gallic acid was chosen as a standard. The data expressed as milligram gallic acid equivalents.

Total flavonoid content was determined by the aluminum chloride colorimetric method described by [11]. $0.5 \mathrm{~mL}$ of the extracts $(0.5 \mathrm{mg} / \mathrm{mL}$ and $1 \mathrm{mg} / \mathrm{mL})$ were mixed with $1.5 \mathrm{~mL}$ of ethanol, $0.1 \mathrm{~mL}$ of $10 \%$ aluminum chloride and $2.8 \mathrm{~mL}$ of distilled water. The mixture was kept at room temperature for $30 \mathrm{~min}$ and the absorbance was recorded at $415 \mathrm{~nm}$ with the help of UNICAM 8625 UV/Vis spectrophotometer. Quercetin equivalent (QE) was chosen as a standard. The amount of flavonoid was expressed as QE.

\subsection{DPPH radical scavenging activity}

The capacity of the C.rubrum extracts to scavenge the DPPH radical was measured according to Blois method with a slight modification [12]. $1 \mathrm{~mL}$ of the extracts $(0.5 \mathrm{mg} / \mathrm{mL}$ and $1 \mathrm{mg} / \mathrm{mL}$ ) were added to a $4 \mathrm{~mL}$ of a $0.004 \%$ methanol solution of DPPH. After $30 \mathrm{~min}$ of incubation in dark at room temperature, the absorbance was read against a blank at $517 \mathrm{~nm}$. Inhibition (I) of a free radical by DPPH in percent I (\%) was calculated as follows:

$$
\text { Inbition } \%=100 \times\left(A_{\text {blank}}-A_{\text {sample }} / A_{\text {blank }}\right)
$$

Where, $\mathrm{A}_{\text {blank }}$ is the absorbance of the control reaction and $\mathrm{A}_{\text {sample }}$ is the absorbance of the test compound. Tocopherol was used for comparison.

\subsection{Determination of antimicrobial activity}

In vitro antimicrobial studies were carried out against eight bacteria strains, Escherichia coli ATCC 8739, Staphylococcus aureus ATCC 6538/P, Streptococcus epidermidis ATCC 12228, Enterococcus faecalis ATCC 29212, Enterobacter cloacae ATCC 13047, Klebsiella pneumonie ATCC 13883, Bacillus cereus ATCC 7064, Pseudomonas aeruginosa ATCC 9027, which were obtained from the Microbiology Department of the Faculty of Science, Ege University.

Determination of the minimum inhibitory concentration (MIC) was carried out according to the method described by NCCLS [13] with some modifications. Dilution series of the extracts were prepared in test tubes and then transferred to the broth in 96-well microtiter plates. Final concentrations in the medium were $512-0.5 \mu \mathrm{g} / \mathrm{mL}$. Before inoculation of the test organisms, the bacteria strains were adjusted to $0.5 \mathrm{McFarland}$ standards (Thermo Oxoid Remel, Basingstoke, Hampshire, UK) and diluted 1:100 (v/v) in Mueller-Hinton broth (Oxoid, Basingstoke, Hampshire, UK). Plates were incubated at $35{ }^{\circ} \mathrm{C}$ for $18-24 \mathrm{~h}$. All tests were performed in broth and repeated twice. The MIC was defined as the lowest concentration that showed clear against a black background (no visible growth). Samples from clear wells were subcultured by plotting on to Mueller-Hinton agar. Gentamycin and Ampicillin were used as standard antibacterial agents. All antibiotics were purchased from Sigma-Aldrich Co. and dilutions were prepared at concentrations ranging from 128 to $0.25 \mu \mathrm{g} / \mathrm{mL}$ in microtiter plates.

\subsection{Bacterial reverse mutation assay (Ames test)}

The assay was performed in two histidine-requiring strains of Salmonella typhimurium, tester strains TA98 and TA100 according to Maron and Ames [14]. Two separate experiments 
were performed, using triplicate plates, in the presence and absence of metabolic activation by an Aroclor 1254 (Sigma-Aldrich Co.)-induced (500 mg/kg body weight) Swiss albino mice liver post-mitochondrial fraction (S9). The post mitochondrial fraction was used at a concentration of $10 \% \mathrm{v} / \mathrm{v}$ in the S9 mixture (metabolic activation). Negative controls and positive controls were tested in all strains in both experiments. Dimethyl sulfoxide (DMSO) was used as a reference negative control. Benzo[a]pyrene (Sigma-Aldrich Co.) (5 $\mu \mathrm{g} / \mathrm{plate}), 2-$ nitrofluorene (Sigma-Aldrich Co.) (5 $\mu \mathrm{g} /$ plate) and sodium azide (Sigma-Aldrich Co.) (10 $\mu \mathrm{g} / \mathrm{plate})$ were used as positive controls. Fresh cultures of tester strains were grown to approximately $109 \mathrm{cell} / \mathrm{mL}$ in $5 \mathrm{~mL}$ Oxoid nutrient broth (Oxoid). The cultures were incubated for $10-12 \mathrm{~h}$ at $37^{\circ} \mathrm{C}$ in a gyratory incubator in order to insure adequate aeration. The strains were periodically raised from a single colony to check the genetic markers.

The extracts with the amounts of $1,2.5$ and $5 \mathrm{mg}$ per plate were tested on TA98 and TA100. All positive and negative controls as well as the extracts were prepared in the absence $(0.5 \mathrm{~mL} /$ plate $)$ and presence of $\mathrm{S} 9$ mixture $(0.5 \mathrm{~mL} /$ plate $)$. The mixtures containing positive and negative controls and extracts and $0.1 \mathrm{~mL}$ of overnight bacterial cultures with or without $\mathrm{S} 9$ was vortexed and pre-incubated at $37^{\circ} \mathrm{C}$ for $30 \mathrm{~min}$. It was then plated in $2 \mathrm{~mL}$ of top agar on glucose-supplemented minimal agar. After $48 \mathrm{~h}$ of incubation at $37^{\circ} \mathrm{C}$, revertant colonies (his ${ }^{+}$) were counted. The results of the test were presented as the mean \pm SEM. Comparisons were made between control and treatment groups using one-way analysis of variance (ANOVA) followed by Dunnett's test. Values of $\mathrm{p} \leq 0.05$ were regarded as statistically significant.

\subsection{HET-CAM (Hen's egg test chorioallantoic membrane) irritation test}

The toxicity and/or irritation effects of each algal extracts revealed by using a chorioallantoic membrane model on fertilized hen eggs. In vivo irritation effects of samples was carried out on fertile Leghron chicken eggs weighing 50-60 gr obtained from commercial sources (Lezita, İzmir, TURKEY) by using HET-CAM method modified of [15]. Fertilised hens' eggs were placed into an incubator with conveyor rotation system at $37 \pm 1^{\circ} \mathrm{C}$ and $80 \pm 2 \%$ humidity for 7 days. On day 7 , the eggs were opened on the snub side sucked off through a hole on the pointed side and then a round piece of shell (3-4 $\mathrm{cm}$ diameter) was removed carefully with forceps. Then, the inner membrane carefully removed with forceps, without injury to the blood vessel. After that, $300 \mu 1$ of the freshly prepared sample at 0.5 and $1 \mathrm{mg} / \mathrm{ml}$ concentration that dissolved in DMSO (0.05\%) $(0.5$ and $1 \mathrm{mg} / \mathrm{ml})$ was applied to the CAM. The irritation severity (IS) for a period of up to 5 min was scored as:

$$
\text { IS }=[(301-h) \times 5] / 300+[(301-1) \times 7] / 300+[(301-c) \times 9] / 300
$$

Where, $\mathrm{h}$ is the time of vascular hemorrhage occurred; 1 is the time of first vascular lysis occurred; and $\mathrm{c}$ is the time of first vascular coagulation occurred. Irritation classification based on IS: $0.0-0.9$, non-irritation; $1.0-4.9$, slight irritation; $5.0-8.9$, moderate irritation; and 9.021.0 , severe irritation. Also, $0.9 \% \mathrm{NaCl}$ as negative control and $0.1 \mathrm{~N} \mathrm{NaOH}$ as positive control at the concentration of $300 \mu \mathrm{L}$ were also tested. For every test compound, 5 eggs were utilized. All samples were tested in triplicate at different times.

\section{RESULTS and DISCUSSION}

Algae which constitute the primary source of marine and freshwater ecosystems have been intensively studied in many pharmacological research as well as consumption as a food supplement. This study was concluded to reveal the biological activities as well as in vivo toxicity of Ceramium rubrum extracts collected from the Aegean coast. 
Antioxidant agents play a vital role in a wide spectrum against various diseases. However, the worrying side effects of synthetic originated products have increased interest in natural origin sources. Previous studies revealed that algae metabolites were effective via metal chelation, scavenging and inhibition of free radical. This activity of the algae is provided by different metabolites such as polysaccharides, polyunsaturated fatty acids, fluorotannins and other phenolic compounds and carotenoids. Similarly, in studies evaluating the antioxidant capacity of algae samples, it has been reported that phenolic contents have significant contributions to antioxidant activity [16,17]. Our results showed that Met extract of $C$. rubrum had higher total phenolic and flavonoid contents than the other extracts as $5.42 \mathrm{mg}$ $\mathrm{GAE} / \mathrm{g}$ and $0.541 \mathrm{mg} \mathrm{QE} / \mathrm{g}$, respectively (Table 1). However, according to antioxidant activity in Table 1, exhibited that Hex extract showed higher antioxidant effective than other extracts. It has been suggested that the increase in DPPH activity may be due to the presence of lipophilic antioxidants such as tocopherol, color pigment and unsaturated fatty rather than the activity of the phenol and flavonoid compounds in the polar solvent. Horincar et al., [18] also declared that while the methanol extracts of C.rubrum had higher phenolic content than hexane similar to our results, methanol had higher efficacy in terms of antioxidant activity unlike our results. These differences can be explained by seasonal differences.

Table 1. Antioxidant activity and content of flavonoid and total phenolic compounds of C.rubrum extract expressed as quercetin (QEmg/g) and gallic acid (GA) equivalents (GAEs; mg of GA/g of extract). (Hex: n-Hexane, Chl: Chloroform, Met: Methanol)

\begin{tabular}{ccccccc}
\hline Sample Concentration & $\begin{array}{c}\text { DPPH Inhibition } \\
(\mathrm{mg} / \mathrm{mL})\end{array}$ & $\begin{array}{c}\alpha \text {-tocopherol } \\
\text { equivalent antioxidant } \\
\text { activity values } \\
(\mu \mathrm{g} / \mathrm{mL})\end{array}$ & $\begin{array}{c}\mathrm{IC}_{50} \\
(\mathrm{mg} / \mathrm{ml})\end{array}$ & $\begin{array}{c}\text { Flavonoid } \\
\text { content } \\
(\mathrm{QEmg} / \mathrm{g})\end{array}$ & $\begin{array}{c}\text { Phenolic } \\
\text { content }(\mathrm{GAE} \\
\mathrm{mg} / \mathrm{g})\end{array}$ \\
\hline \multirow{3}{*}{$\mathrm{Hex}$} & 0.25 & $3.07 \pm 0.02$ & $1.76 \pm 0.02$ & $4.83 \pm$ & $0.08 \pm 0.01$ & $1.28 \pm 0.04$ \\
& 0.5 & $2.12 \pm 0.01$ & $3.24 \pm 0.02$ & 0.01 & & \\
\hline & 1 & $9.46 \pm 0.03$ & $9.32 \pm 0.03$ & & & \\
\hline & 0.25 & $4.56 \pm 0.01$ & $4.87 \pm 0.05$ & $6.72 \pm$ & $0.121 \pm 0.02$ & $2.14 \pm 0.03$ \\
& 0.5 & $9.11 \pm 0.03$ & $8.14 \pm 0.05$ & 2.58 & & \\
\hline & 1 & $10.26 \pm 0.02$ & $10.23 \pm 0.06$ & & & \\
\hline \multirow{2}{*}{ Met } & 0.25 & $5.21 \pm 0.04$ & $4.12 \pm 0.02$ & 11.52 & $0.541 \pm 0.02$ & $5.42 \pm 0.05$ \\
& 0.5 & $6.32 \pm 0.02$ & $6.43 \pm 0.01$ & \pm 1.92 & & \\
\hline
\end{tabular}

Each value is the average of three analyses \pm standard deviation. IC 50 values for standart compound equivalent to the Hex, Chl and Met extract were $4.94 \pm 0.02,6.81 \pm 0.02$ and $5.83 \pm 0.01$, respectively.

Marine algae have developed resistance to the continuous exposure to pathogenic agents such as bacteria, fungi and yeast in the ecosystem. These features of algae have become a focus of attention for use in human health and previously study showed that marine macro algae can prevent the development of some bacteria $[19,20]$. As seen Table 2, C. rubrum extracts showed moderate antimicrobial activity against assayed Gram (+) and Gram (-) microorganisms by MIC method. Tuney et al. [21] revealed that methanol extracts of the C.rubrum has moderate antibacterial activity against $E$. coli and $P$. aeruginosa. Several authors have reported that antimicrobial activity of algae is significantly changed by factors such as seasonality, extraction methods and location [22, 23]. Also, given the suggestions of the Amico et al. [24], presence of different compounds in polar and apolar solvent significantly affect antimicrobial activity. 
Table 2. Minimum inhibitory concentration (MIC) results of C. rubrum extracts.

\begin{tabular}{lcccc}
\hline & \multicolumn{4}{c}{ MIC $(\mu \mathrm{g} / \mathrm{ml})$} \\
Microorganisms & Hex & Chl & Met & Gentamycin \\
\hline Escherichia coli ATCC 23999 & 256 & 256 & 256 & 1.0 \\
Klebsiella pneumonie CCM 2318 & 256 & 256 & 128 & 1.0 \\
Pseudomonas aeroginosa ATCC 27853 & 256 & 256 & 256 & 1.0 \\
Salmonella typhimurium CCM 5445 & 256 & 128 & 256 & 1.0 \\
Bacillus cereus ATCC 7064 & 64 & 128 & 64 & 4.0 \\
Staphylococcus aureus ATCC 6538/P & 64 & 256 & 128 & 4.0 \\
Enterococcus faecalis ATCC 29212 & 128 & 128 & 64 & 16.0 \\
Staphylococcus epidermidis ATCC 12228 & 256 & 256 & 128 & 2.0 \\
\hline
\end{tabular}

The antimutagenic effects of $C$. rubrum were also assessed using Salmonella typhimurium TA 98 and TA 100 strains in the absence and presence of S9. Our result reported that the chemical concentrations and his + revertants of the extracts demonstrated no mutagenicity compared to the controls, even $5 \mathrm{mg} / \mathrm{mL}$ concentration (Table 3). Similarly, Syad and Kasi [25] reported that red algae species did not lead to any mutagenicity in TA 98, TA 100 and TA 1538 strains.

Table 3. His + revertants in the Bacterial reverse mutation assay of C. rubrum extracts and control groups. (Hex: n-Hexane, Chl: Chloroform, Met: Methanol)

\begin{tabular}{|c|c|c|c|c|c|}
\hline \multirow{3}{*}{ Extracts } & \multirow{3}{*}{ Concentration $(\mu \mathrm{g} / \mathrm{mL})$} & \multicolumn{4}{|c|}{ his + revertants/plate $(\mathrm{X} \pm \mathrm{SEM})$} \\
\hline & & \multicolumn{2}{|c|}{ TA98 } & \multicolumn{2}{|c|}{ TA 100} \\
\hline & & $-\mathrm{S} 9$ & $+\mathrm{S} 9$ & $-S 9$ & $+\mathrm{S} 9$ \\
\hline \multirow[t]{2}{*}{ DMSO } & 10 & $31 \pm 2$ & $42 \pm 3$ & $112 \pm 6$ & $104 \pm 8$ \\
\hline & 1 & $42 \pm 1$ & $15 \pm 1$ & $138 \pm 10$ & $112 \pm 9$ \\
\hline \multirow[t]{3}{*}{ Hex } & 2.5 & $54 \pm 3$ & $22 \pm 4$ & $121 \pm 8$ & $142 \pm 10$ \\
\hline & 5 & $56 \pm 2$ & $34 \pm 3$ & $110 \pm 9$ & $160 \pm 12$ \\
\hline & 1 & $20 \pm 1$ & $20 \pm 1$ & $114 \pm 7$ & $122 \pm 8$ \\
\hline \multirow[t]{3}{*}{ Chl } & 2.5 & $22 \pm 1$ & $42 \pm 1$ & $122 \pm 8$ & $121 \pm 9$ \\
\hline & 5 & $38 \pm 3$ & $54 \pm 2$ & $124 \pm 8$ & $158 \pm 14$ \\
\hline & 1 & $50 \pm 2$ & $60 \pm 3$ & $191 \pm 9$ & $108 \pm 8$ \\
\hline \multirow[t]{2}{*}{ Met } & 2.5 & $41 \pm 4$ & $17 \pm 2$ & $196 \pm 8$ & $107 \pm 7$ \\
\hline & 5 & $32 \pm 1$ & $16 \pm 2$ & $121 \pm 10$ & $146 \pm 9$ \\
\hline
\end{tabular}

\begin{tabular}{lcllc} 
Chemicals & $\begin{array}{c}\text { Concentration/plate } \\
(\mu \mathrm{g})\end{array}$ & Strain & S9 & his + revertants/plate $(\mathrm{X} \pm \mathrm{SEM})$ \\
\hline Benzo[a]pyrene & 5 & TA98 & + & $742 \pm 22$ \\
& 5 & TA100 & + & $658 \pm 46$ \\
\hline 2-Nitrofluorene & 5 & TA 98 & - & $926 \pm 34$ \\
Sodium azide & 10 & TA 100 & - & $1026 \pm 48$ \\
\hline
\end{tabular}

HET-CAM irritation/toxicity method was performed to prove toxicity such as lysis, coagulation and haemorrhage in response to the application of algae extracts, and the scores obtained were calculated separately for each algae extract (Figure1). Extracts had no lead to any irritation even at the highest concentrations for a period of up to $5 \mathrm{~min}$. However, while the DMSO and negative group no irritation were determined, the positive control immediately interacting with the CAM resulted in hemorrhage, lysis and coagulation, respectively and cause severe irritation with the IS score of $17.8 \pm 0.1$ for a period of up to $5 \mathrm{~min}$. 

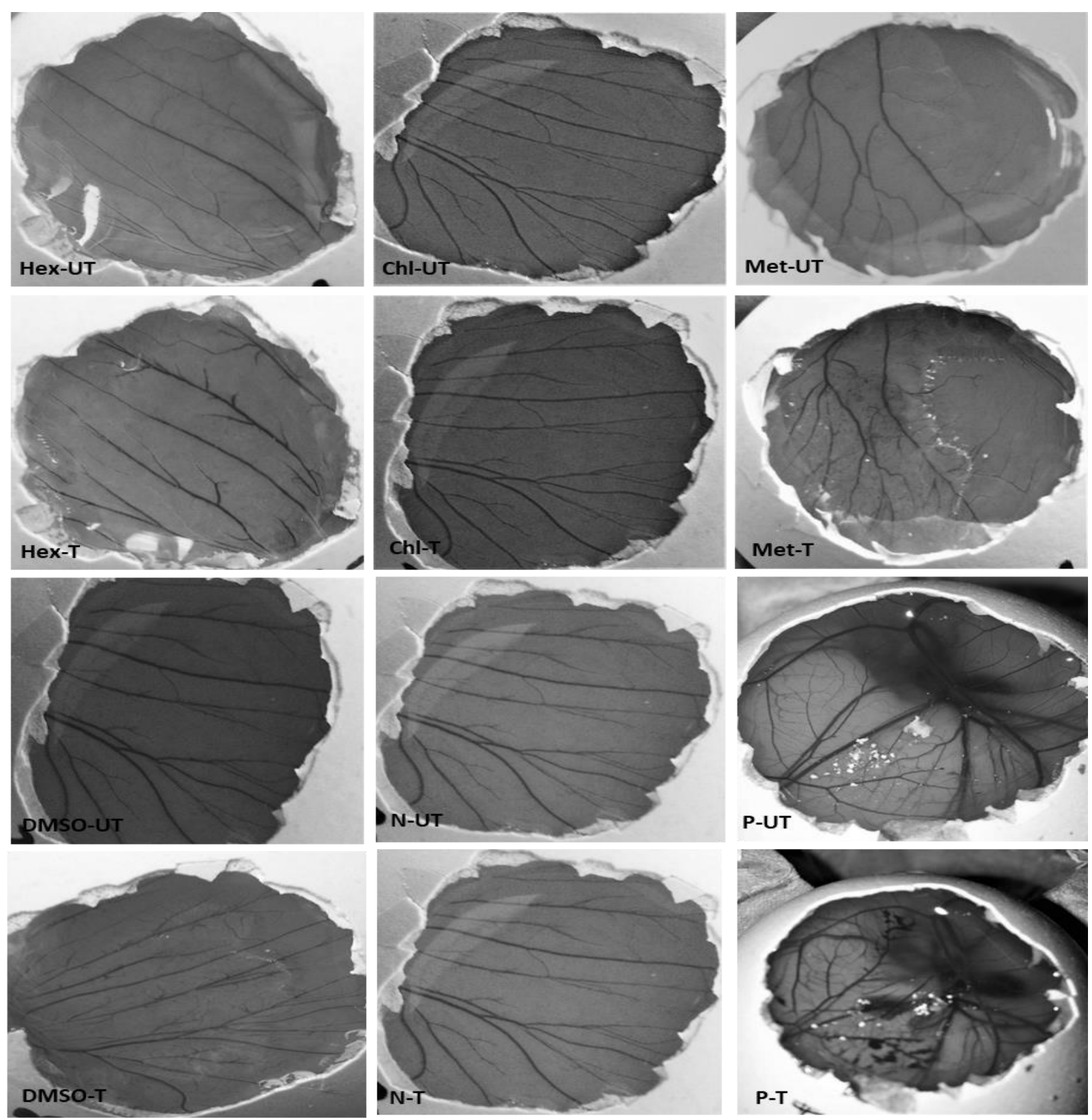

Figure 1. Photographs illustrating of the potential irritation or toxicity on vascularization before exposure to the test samples $(0 \mathrm{~min})$ and after the exposure for up to $5 \mathrm{~min}$ by HET-CAM assay. Hex: $n$-Hexane, Chl: Chloroform, Met: Methanol, UT: before traetment, T: after treatment, N: Negative control $(0.9 \% \mathrm{NaCl}), \mathrm{P}$ : Positive control $(0.1 \mathrm{~N} \mathrm{NaOH})$

In present study, antioxidant, antimicrobial and antimutagenic activity as well as irritation/toxicity of C.rubrum collected from Urla of Aegean Sea were investigated. Given the increasing interest in studies related to the discovery and potential use of new compounds from marine algae, our results is a preliminary opinion for the synthesis of new active compounds from common algal species in our country. This result may also supported that C. rubrum which extracts does not cause any irritation/toxicity can be used as a reliable natural antioxidant compound.

\section{ORCID}

Adem Güner (D) https://orcid.org/0000-0003-3295-3538 


\section{REFERENCES}

[1] Blunt, J.W., Copp, B.R., Hu, W.P., Munro, M.H.G., Northcote, P.T., Prinsep, M.R. (2007). Marine natural products, Nat. Prod. Rep. 24, 31-86.

[2] Cardozo, K.H.M., Guaratini, T., Barros, M.P., Falcão, V.R., Tonon, A.P., Lopes, N.P., Campos, S., Torres, M.A., Souza, A.O., Colepicolo, P., Pinto, E. (2007). Metabolites from algae with economical impact. Comp. Biochem. Physiol. C: Toxicol. Pharmacol. 146, 6078.

[3] Yuan, Y.V., Walsh, N. (2006). Antioxidant and antiproliferative activities of extracts from a variety of edible seaweeds. Food Chem. Toxicol. 44, 1144-1150.

[4] Fisch, K.M., Böhm, V., Wright, A.D., König, G.M. (2003). Antioxidant meroterpenoids from the Brown alga Cystoseira crinite. J. Nat. Prod. 66, 968-975.

[5] Kang, K., Park, Y., Hwang, H.J., Kim, S.H., Lee, J.G., Shin, H.C. (2003). Antioxidative properties of brown algae polyphenolics and their perspectives as chemopreventive agents against vascular risk factors. Arch. Pharm. 26, 286-293.

[6] Cox, S., Abu-Ghannam, N., Gupta, S. (2010). An Assessment of the Antioxidant and Antimicrobial Activity of Six Species of Edible Irish Seaweeds. International Food Research Journal, 17, 205-220.

[7] Manivannan, K., Karthikai Devi, K., Anantharaman, G., P., Balasubramanian, T. (2011). Antimicrobial potential of selected brown seaweeds from Vedalai coastal waters, Gulf of Mannar. Asian Pac. J. Trop. Biomed. 1, 114-120.

[8] Mohamed, S., Hashim, S.N., Rahman, H.A. (2012). Seaweeds: A sustainable functional food for complementary and alternative therapy. Trends in Food Science \& Technology, 23, 83-96.

[9] Osuna-Ruiza, I., Lopez-Saizb, C.M., Burgos-Hernandez, A., Velazquez, C., Nieves-Soto, M., Hurtado-Oliva, M.A. (2016). Antioxidant, antimutagenic and antiproliferative activities in selected seaweed species from Sinaloa, Mexico. Pharmaceutical Biology, 54, 2196-2210.

[10] Meda, A., Lamien, C.E., Romito, M., Millogo, J., Nacoulma, O.G. (2005). Determination of the total phenolic, flavonoid and proline contents in Burkina Fasan honey, as well as their radical scavenging activity. Food Chem. 91, 571-577.

[11] Chang, C.C., Yang, M.H., Wen, H.M., Chern, J.C. (2002). Estimation of total flavonoid content in propolis by two complementary colorimetric methods. J. Food Drug Anal. 10, 178-182.

[12] Turkoğlu, A., Kıvrak, I., Mercan, N., Duru, M.E., Gezer, K., Turkoğlu, H. (2006). Antioxidant and antimicrobial activities of Morchella conica. Pers. Afr. J. Biotechnol. 5, 1146-1150.

[13] NCCLS, National Committee for Clinical Laboratory Standards, Methods for dilution antimicrobial susceptibility tests for bacteria that grow aerobically; approved standard. NCCLS document M7-A6, 8th edn. NCCLS, Wayne, PA, 2003.

[14] Maron, D.M., Ames, B.N. (1983). Revised methods for the Salmonella mutagenicity test. Mutat. Res. 113, 173-215.

[15] Kishore, A.S., Surekha, P.A., Sekhar, P.V., Srinivas, A., Murthy, P.B. (2008). Hen egg chorioallantoic membrane bioassay: An in vitro alternative to Draize eye irritation test for pesticide screening. Int. J. Toxicol. 27, 449-453.

[16] Michalak, I., Chojnacka, K. (2015). Algae as production systems of bioactive compounds, Eng. Life Sci. 15, 160-176.

[17] Pérez, M.J., Falqué, E., Domínguez, H. (2016). Antimicrobial Action of Compounds from Marine Seaweed. Mar. Drugs, 14, 52. 
[18] Horincar, V.B., Parfene, G., Bahrim, G.E. (2011). Evaluation of bioactive compound inextracts obtained from three romanian marine algae species. Romanian Biotechnological Letters, 16, 6.

[19] Rhimou, B., Hassane, R., Jose, M., Nathalie, B. (2010). The antibacterial potential of the seaweeds (Rhodophyceae) of the Strait of Gibraltar and the Mediterranean coast of Morocco. Afr. J.Biotechnol. 9, 6365-6372.

[20] Karthikeyan, K., Shweta, K., Jayanthi, G., Prabhu, K., Thirumaran, G. (2015). Antimicrobial and antioxidant potential of selected seaweeds from Kodinar, Southern Coast of Saurashtra, Gujarat, India. J. Appl. Pharm. Sci. 5, 35-40.

[21] Caccamese, S., Toscano, R.M., Furnari, G., Cormaci, M. (1985). Antimicrobial activities of red and brown algae from Southern Italy coast. Bot. Mar. 28, 505-507.

[22] Tüney Kızılkaya, I., Hilal Cadirci, B.H., Unal, D., Sukatar, A. (2007). Locational and organic solvent variation in antimicrobial activities of crude extracts of marine algae from the coast of Izmir (Turkey). Fresenius Environmental Bulletin, 16, 428-434.

[23] Febles, C.I., Arias, A., Gil-Rodriguez, M.C., Hardisson, A., Sierra Lopez, A. (1995). In vitro study of antimicrobial activity in algae (Chlorophyta, Phaeophyta and Rhodophyta) collected from the coast of Tenerife (in Spanish). Anuario del Instituto de Estudios Canarios, 34, 181-192.

[24] Amico, V., Neri, P., Piattelli, M., Ruberto, G. (1987). Geranylgeraniol-derived diterpenes from the brown alga Bifurcaria Bifurcata: comparison with two other Cystoseiraceae species. Phytochemistry, 26, 2637-2639.

[25] Syad, A.N., Kasi, P.D. 2014. Assessment of Mutagenic Effect of G. acerosa and S. wightii in S. typhimurium (TA 98, TA 100, and TA 1538 strains) and Evaluation of Their Cytotoxic and Genotoxic Effect in Human Mononuclear Cells: A Non-Clinical Study. Biomed Res. Int. 313942, doi: 10.1155/2014/313942. 